\title{
Hydroxypropyl Methylcellulose in Extracapsular Cataract Surgery with Intraocular Lens Implantation: Intraocular Pressure and Inflammatory Response
}

\author{
L. C. CHUMBLEY, A. M. MORGAN, I. MUSALlAM \\ Jerusalem
}

\begin{abstract}
Summary
We studied prospectively the effects of $2 \%$ hydroxypropylmethylcellulose (HPMC), instilled in to the anterior chamber during extracapsular cataract extraction with posterior chamber intraocular lens implantation in 122 patients. Significant pressure rise was noted at 12 and 24 hours post-operatively when HPMC was not removed at the end of surgery. This was prevented by washing HPMC from the anterior chamber at the end of surgery, or by using either acetazolamide or a combination of oxyphenbutazone and vitamin $C$ without washing HPMC. There was no difference in intraocular inflammation between controls and the HPMC groups. The group receiving acetazolamide without washing HPMC had the most inflammation, while the group receiving combined oxyphenbutazone and vitamin $\mathrm{C}$ had the least, the differences between these two groups being sufficient.
\end{abstract}

Visco-elastic substances offer a number of advantages to the ophthalmic surgeon, such as gentle creation or maintenance of surgical spaces, tissue planes, and protection of tissues. ${ }^{1}$ Three visco-elastic substances are currently in use: sodium hyaluronate $(\mathrm{SH})$, hydroxypropylmethyl-cellulose (HPMC), and chondroitin sulphate (CS).

Fleming and co-workers in 1.959 showed that $0.5 \%$ HPMC did not cause significant inflammation in rabbit eyes and was undetectable after three days, suggesting it exited through the normal ocular outflow pathways. ${ }^{2}$

Robert and co-workers ${ }^{3}$ injected $2 \%$ HPMC into rabbit anterior chambers and observed corneal oedema and anterior chamber fibrin during the first week. Histopath- ologic studies of the eyes at 3,6, 13 and 25 days were normal.

SH $1 \%$, HPMC $2 \%$ and CS 3-4\% protected cat corneal endothelium equally from mechanical trauma. ${ }^{4}$ Intraocular inflammation increased mildly in all of the cats' eyes. High intraocular pressures, first appearing after four hours and lasting 8-24 hours, were reduced by anterior chamber washout of the four preparations.

HPMC $0.4 \%$ mildly protected rabbit endothelium. ${ }^{5}$ Pressure rose much less than $\mathrm{SH}$ or . $10-20 \%$ CS (viscosity $0.4 \%<2 \%$ HPMC, 40 vs $4000 \mathrm{cp}$ ). Pressure peaks at one to four hours when tested the following day were missed and pressures returned to normal after 14 hours.

HPMC $2 \%$ protected cat and monkey

From: St John Ophthalmic Hospital, Jerusalem.

Presented in part at the Seventh European Intraocular Lens Implant Council, Zürich, Switzerland, August 1989.

Correspondence to: L. C. Chumbley, Kottwitz Str. 16, 2000 Hamburg 20, W. Germany. 


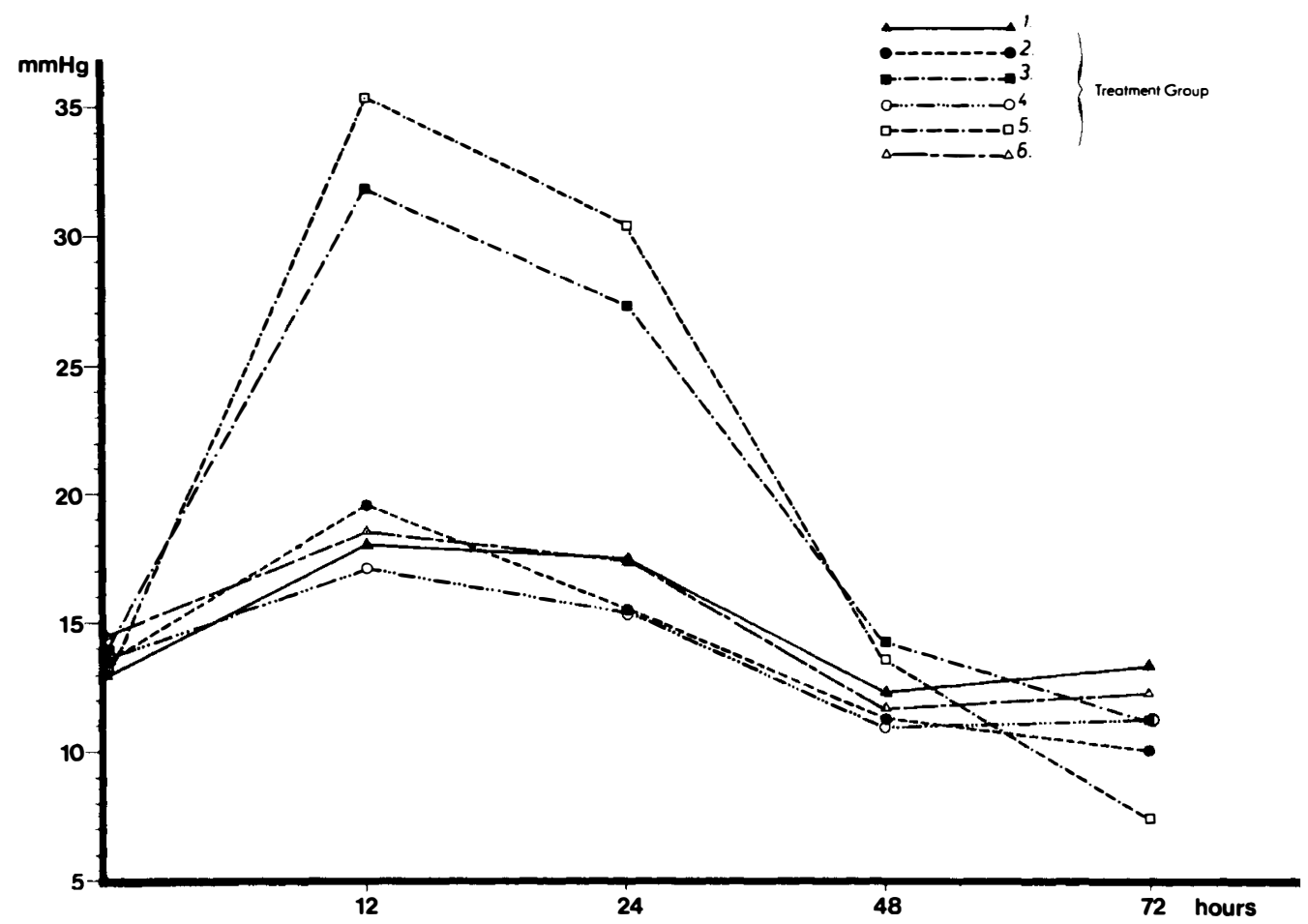

Fig. 1 Mean intraocular pressures in treatment groups showing measurements pre-and postoperatively. Refer to text for details of treatment groups.

endothelium, and caused no serious inflammation after phakoemulsification or extracapsular cataract extraction with posterior chamber lens implantation (ECCE/PCIOL) ${ }^{6}$

Human donor corneas tolerated perfusion with $0.5 \%$ HPMC for three and a half hours well (corneal thickness and supravital endothelial staining) ${ }^{7}$ Steele reported complication-free use of $2 \%$ HPMC in keratoplasty patients. ${ }^{8}$

HPMC $1 \%$ protected endothelium better than air in ECCE/PCIOL patients. Pressure was not measured in the initial post-operative hours. At two days, 5/75 HPMC and 8/75 air patients had pressures $>22 \mathrm{mmHg}$ but these returned to normal after six days. ${ }^{9}$

Liesegang and co-workers ${ }^{10}$ compared $2 \%$ $\mathrm{HPMC}$ and $1 \% \mathrm{SH}$ in ECCE/PCIOL patients. Neither group showed excessive inflammation/toxicity, central endothelial cell loss being equal in the two groups. Intraocular pressure, not measured in the initial postoperative hours, was normal after three days.

Bigar and co-workers ${ }^{11}$ studied 2\% HPMC in 65 patients. Intraocular pressure, not measured in the initial postoperative hours, was occasionally elevated one day post-operatively, and was normal the second postoperative day. No differences from controls were found (epithelial oedema, thickness, Descemet's folds, anterior chamber, pupil, iris, vitreous, fundus).

Fèchner and Rimpler ${ }^{12}$ found no significant differences in anterior chamber inflammatory reaction between $\mathrm{SH}$ and 2\% HPMC in 100 ECCE/PCIOL patients.

Thomsen and co-workers ${ }^{13}$ found no differences in anterior chamber inflammation or intraocular pressure between $\mathrm{SH}$ and $2 \%$ HPMC in $30 \mathrm{ECCE} / \mathrm{PCIOL}$ patients. Day of surgery pressure was not measured. All 15 HPMC patients had reduced pressure beginning by the first postoperative day.

HPMC is the least expensive of the three visco-elastic substances. Judgement of cost; benefit: risk is an important surgical responsibility. We report a study designed to evaluate prospectively $2 \% \mathrm{HPMC}$ in ECCE/PCIOL patients, including a set of day of surgery observations. 


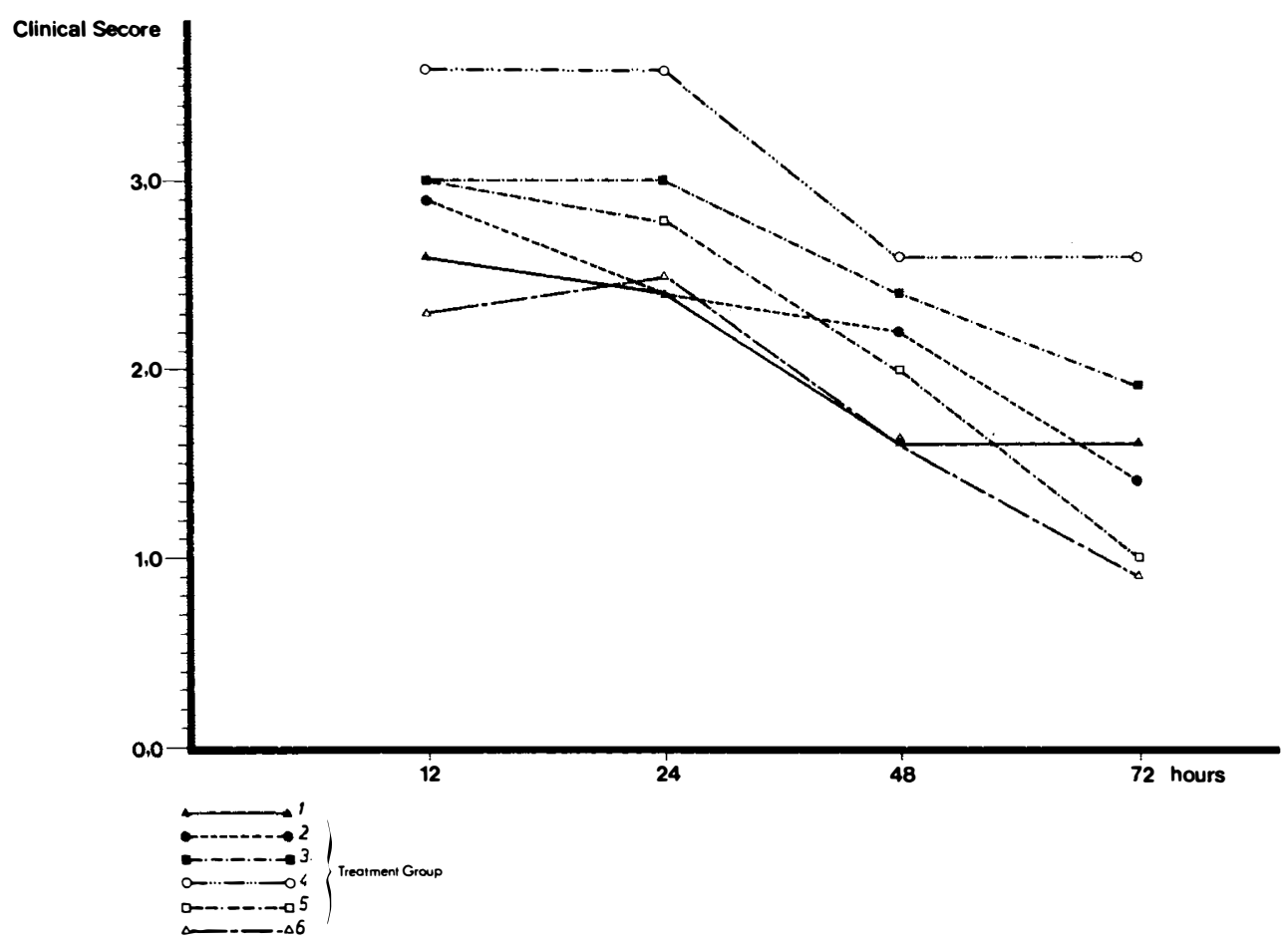

Fig. 2 Mean values of cellular reaction in the anterior chamber in treatment groups post-operatively. Refer to text for details of treatment groups.

\section{Materials and Methods}

All patients included in the study underwent routine extracapsular cataract extraction, followed by insertion of a Sinsky-style posterior chamber intraocular lens.

Two per cent HPMC was prepared according to the method of Fechner. ${ }^{14}$ With use of a syringe, we performed positive pressure filtration of the solution through a $1.2 \mu$ polyfluorotetraethylene (PTFE) membrane filter (Sartorius Corp).

Patients were allocated to one of the following groups:

(1) Control group, HPMC was not used, only balanced salt solution employed.

(2) HPMC used but completely removed at end of operation.

(3) HPMC used but not removed.

(4) HPMC used but not removed, acetazolamide $250 \mathrm{mg}$ given by mouth every six hours for 36 hours post-operatively.

(5) HPMC used but not removed, oxyphenbutazone $50 \mathrm{mg}$ given by mouth every six hours for 72 hours post-operatively.

(6) As for group five but also with use of vita- min C 500 mg given by mouth 30 minutes pre-operatively, and then every six hours post-operatively for 72 hours.

A detailed proforma was completed for every patient, three sets of observations were recorded at the following times: 12 hours preoperatively; and 12, 24, 48 and 72 hours postoperatively. The three sets of observations were: intraocular pressure (Goldmann tonometry), anterior chamber cellular reaction, and anterior chamber flare (both the latter defined according to currently accepted criteria. ${ }^{15}$ The treatment group was known neither to the patient nor the observer.

\section{Results}

There were 122 patients in the study (59 males, 63 females). Breakdown by treatment groups was: Group 1, 36 patients; Group 2, 28; Group 3, 16; Group 4, 21; Group 5, 8; Group 6, 13 patients.

The results of serial measurements of intraocular pressure, anterior chamber cellular reaction, and anterior chamber flare are shown in Figures 1, 2 and 3, respectively. Sig- 


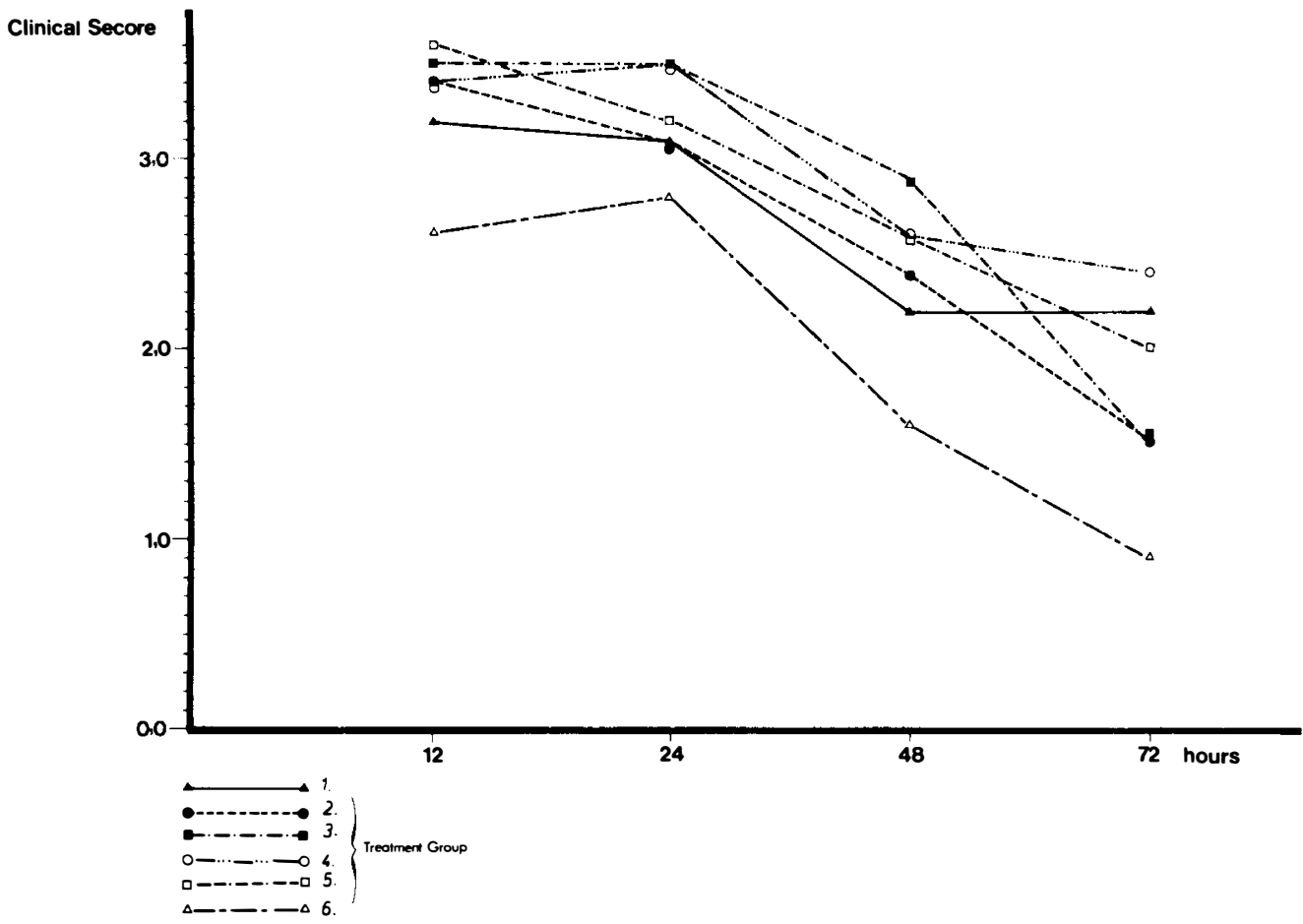

Fig. 3 Mean values of flare in the anterior chamber in treatment groups post-operatively. Refer to text for details of treatment groups.

nificant differences in intraocular pressure were found between Groups 3 and 5 on the one hand and Groups 1, 2, 4 and 6 on the other hand, at 12 and at 24 hours after surgery. Significant differences in both anterior chamber cells and flare were found between Group 4 and Group 6 at 72 hours after surgery.

\section{Discussion}

In this prospective study we analysed the effects of instillation of a $2 \%$ solution of HPMC into the anterior chamber during extracapsular cataract surgery, followed by insertion of a posterior chamber intraocular lens. HPMC was very easy to use. Satisfactory maintenance of the anterior chamber by HPMC was observed in all cases, which made insertion of a posterior chamber intraocular lens easier.

A rise in intraocular pressure was observed at 12 and 24 hours post-operatively, in Group 3 in which HPMC was used but not removed, and in Group 5 in which HPMC was used together with use of oxyphenbutazone alone in the post-operative period (Fig. 1). However, the degree of rise in intraocular pressure was not different between these two groups.

The rise in post-operative intraocular pressure observed in Groups 3 and 5 differed significantly from the remaining four treatment groups (Fig. 1), in whom no such rise was observed and among whom no significant inter-group differences were found. It would therefore appear that the observed rise in intraocular pressure at 12 and 24 hours postoperatively may be prevented equally well by either washing HPMC from the anterior chamber at the end of surgery, or by not removing it but using either acetazolamide $250 \mathrm{mg}$ every six hours post-operatively, or as combination of oxyphenbutazone $50 \mathrm{mg}$ every eight hours and vitamin C $500 \mathrm{mg}$ (once 30 minutes pre-operatively, then every six hours) in the post-operative period. These results raise the question of whether vitamin $\mathrm{C}$ alone would exert the same preventive action.

There were no significant differences 
observed between the control Group 1 and the HPMC treatment groups $2-5$ as regards the appearance of cells and flare in the anterior chamber (Figs. 2 and 3). HPMC 2\% does not appear therefore to be toxic to the anterior chamber structures. Group 4 receiving acetazolamide without washing HPMC had the most inflammation, while Group 6 receiving combined oxyphenbutazone and vitamin $C$ had the least, the differences between these two last groups being significant (Figs. 2 and 3).

Fechner ${ }^{16}$ found elevated intraocular pressure in 63 patients after ECCE and iris claw (not posterior chamber) lens implantation with use of $2 \%$ HPMC (mean IOP morning of first post-operative day 36.8) but not in 26 patients receiving a secondary iris claw lens implantation also using 2\% HPMC (mean IOP morning of first post-operative day 21.6). He attributed the rise in the first group to the primary surgery and not to HPMC, since both groups received $2 \%$ HPMC and the same IOL type but differed only in the type of operative procedure performed. His findings could also be interpreted as a temporary overload of the oùtflow structures by HPMC plus lens matter/ inflammatory products compared to just HPMC.

Rosen and co-workers ${ }^{17}$ found impurities and particulate matter in six samples of $2 \%$ HPMC from European pharmacies. They questioned its safety for intraocular use; they compared the six samples with a commercial sample of methylcellulose eyedrops specifically not recommended for intraocular use and incubated the materials with chloramphenicol, ethanol, and beta-glucosidase enzyme solution. Overnight incubation of this mixture produced gross particulate precipitated material present to an equal degree in the unfiltered eyedrops not intended for intraocular use and the allegedly filtered solutions whose labels indicated that they were for intraocular use. Many obvious glass fragments present in the samples indicated that the containers had not been adequately cleaned.

Fechner and Rimpler ${ }^{12}$ tested 2\% HPMC solutions made by a hospital pharmacy and an industrially prepared solution. They examined samples withdrawn from the bottom of test tubes containing ultracentrifuged HPMC and found no particles or sediments or fibres with use of light or interference phase contrast microscopy. Gram and MGG staining of the samples was negative. Amino acid analysis showed no proteins or amino acids of botanical origin. On the other hand, they found that even a single filter paper fibre artefactually added to the solutions was easily demonstrable by their techniques. Such artefactually added filter paper fibres resulted in fibre clusters resembling those shown by Rosen and coworkers. ${ }^{17}$ They suggested that the solutions examined by Rosen and co-workers had, among other things, not been properly filtered.

Technical details of preparation are extremely important. Details regarding use of highest quality reagent grades of HPMC are provided by Fechner ${ }^{14}$ and should be followed. HPMC reagent powder routinely available on the market is not of this quality. Methylcellulose eyedrops not intended for intraocular use contain in addition endothelium-toxic preservatives and are of course absolutely contraindicated for intraocular use. In no way should filter paper be used for filtration. We injected 2\% HPMC solution through $1.2 \mu$ polyfluorotetraethylene (PTFE) membrane filters (Sartorius Corp) with a syringe using positive pressure, thereby eliminating the step of negative suction which Rosen $^{17}$ suggested may have introduced the particulate matter which he observed in the specimens he examined. We examined the solutions we prepared and found them to be completely clear and free of microscopic particles.

Properly prepared 2\% HPMC gives excellent results, but not if the necessary expertise and supervision are lacking. This material is available from industrial sources in several countries (for example Adatomed Co., West Germany; Barnes-Hind Co., USA; Dispersa Co., Switzerland; Faure Laboratories, France; Storz Co., USA).

HPMC is less expensive than other viscoelastic substances currently available. It has proven very simple to use in our experience. A rise in intraocular pressure occurring at 12 and 24 hours post-operatively may be prevented by washing HPMC from the eye at the end 
of surgery, or by leaving HPMC in the eye and using either acetazolamide or a combination of oxyphenbutazone and vitamin $C$ in the post-operative period. Because of the design of our study, we are unable to comment on the pressure status sooner than 12 hours postoperatively. Our results suggests that this should be looked at in future studies.

A 2\% HPMC solution. is water soluble and easy to wash out at the conclusion of surgery. on the other hand, there are times (for example, a restless patient, positive vitreous pressure, a complicated procedure, a repeatedly collapsing anterior chamber which has just been satisfactorily reformed, or an already surgically closed wound) when it is safer or more judicious to make no further surgical manoeuvres within the eye. Retention of HPMC and medical prevention of pressure rise as described above would offer a safe alternative to HPMC removal. Acetazolamide or combined oxyphenbutazone/vitamin $\mathrm{C}$ accomplish this equally well, but use of combined oxyphenbutazone/vitamin C results in significantly less inflammation than use of acetazolamide. Perhaps one should use the above mentioned medical treatment prophylactically anyway in cases where HPMC is removed at the end of the procedure but considerable lens matter remains in the eye, or in cases of chronic glaucoma (for whom postoperative pressure rises are known to occur with other viscoelastic substances despite their removal) ${ }^{18}$ or in which optic nerve damage is already evident or suspected before surgery. According to the results of our study, $2 \%$ HPMC does not appear to have any toxic effects upon the structures of the anterior chamber.

\footnotetext{
References

${ }^{1}$ Eisner G: General considerations concerning viscous materials in ophthalmic surgery. Trans Ophthalmol UK 1983, 103: 247-??

${ }^{2}$ Fleming TC, Merrill DL, Gerard LJ: Studies of the irritating action of methylcellulose. Arch Ophthalmol 1959, 61: 565-7.

${ }^{3}$ Robert Y, Gloor B, Wachsmuth ED, Herbst M: Die Überprüfung der Verträglichkeit von intraokular injizierter Hydroxy-propyl-methyl-cellulose (HPMC) im Tierversuch. Klin Mbl Augenheilk 1988, 192: 337-9.

${ }^{4}$ Glasser DB, Matsuda M, Edelhauser HF: A comparison of the efficacy and toxicity of and intraocular pressure response to viscous solutions in
}

the anterior chamber. Arch Ophthalmol 1986, 104: 1819-24.

${ }^{5}$ MacRae SM, Edelhauser HF, Hyndiak RA, Burd EM, Schultz RO: The effects of sodium hyaluronate, chondroitinsulfate and methylcellulose on the corneal endothelium and intraocular pressure. Am J Ophthalmol 1983, 95: 332-41.

${ }^{6}$ Smith SG, Lindstrom RA, Miller S, Hazel S, Skelnik P, Williams P, Mindrup E: Safety and efficacy of $2 \%$ methylcellulose in cat and monkey cataract implant surgery. J Am Intraocul Implant Soc 1984, 10: $160-? ? ?$ ?

${ }^{7}$ Schimmelpfennig B: In vitro untersuchungen über die vertäglichkeit von hydroxypropylmethylcellulose (HPMC) gegenüber menschlichen hornhautendothel. Klin Mbl Augenheilk 1988, 192: 668-71.

${ }^{8}$ Steele ADM: Visco-elastic materials in keratoplasty. Trans Ophthalmol Soc UK 1983, 103: 268-9.

${ }^{9}$ Aron-Rosa D, Cohn HC, Aron JJ, Bouquety C: methylcellulose instead of Healon in extracapsular surgery with intraocular lens implantation. Ophthalmology 1983, 90: 1235-8.

${ }^{10}$ Liesegang TJ, Bourne WM, Ilstrup DM: The use of hydroxypropyl methylcellulose in extracapsular cataract extraction with intraocular lens implantation. Am J Ophthalmol 1986, 102: 723-6.

${ }^{11}$ Bigar F, Hatt R, Robert Y, Schimmelpfennig B, Gloor B, Duba I: Experimentelle und klinische verträglichkeitsprüfung einer gereinigten hydroxypropylmethylcellulose (HPMC) für die vorderabschnlittchirurgie. In Jakobi KW, Schott K, Gloor B. eds. Proc.1. Kongreß der Deutschen Gesellschaft für Intraokularlinsen Implantation. Berlin: Springer 1987, 86-9.

${ }^{12}$ Fechner PU, Rimpler M: Methylzellulose (adatocel) und healon im vergleich. In Jakobi KW, Schott K, Gloor B. eds. Proc.1. Kongreß der Deutschen gesellschaft für intraokularlinsen Implantation. Berlin: Springer 1987, 82-5.

${ }^{13}$ Thomsen M, Simonsen AH, Andreassen TT: Comparison of sodium hyaluronate and methylcellulose in extracapsular cataract extraction. Acta Ophthalmol 1987, 65: 400-5.

${ }^{14}$ Fechner PU: Methylcellulose a viscous cushioning material in ophthalmic surgery. Trans Ophthalmol Soc UK 1983, 103: 259-63.

${ }^{15}$ Schlaegel TF: Symptoms and signs of uveitis. In Duane TD, Jaeger EA, eds. Clinical Ophthalmology. Volume 4. Philadelphia: Harper and Row 1984, Chapter 32. p.2.

${ }^{16}$ Fechner PU: Comparison of the effects of viscoat and healon on postoperative pressure. Letter to the editor. Am J Ophthalmol 1986, 102: 404-5.

${ }^{17}$ Rosen ES, Gregory RPF, Barnett F: Is $2 \%$ hydroxypropylmethylcellulose a safe solution for intraoperative clinical applications? J Cataract Refr Surg 1986, 12: 679-84.

${ }^{18}$ Krupin T, Feitl ME, Bishop KI: Postoperative intraocular pressure rise in open angle glaucoma patients after cataract or combined cataract-filtration surgery. Ophthalmology 1989, 96: 579-84. 